\title{
Propuesta teórica para la categorización y el etiquetado semántico de los archivos familiares a través del Fondo Kati.
}

\author{
Joseba Martínez de Lahidalga Santillana \\ https://orcid.org/0000-0003-2750-9432 \\ Archivero en la Fundación Sancho el Sabio, Vitoria-Gasteiz, España. \\ josebalm07@gmail.com
}

Resumen: La reciente tendencia que está incrementando la visibilidad y la preservación de los archivo familiares está produciendo un nuevo desafío para los archiveros, ya que además de procurar la gestión y conservación física de esta tipología de archivos, tienen que introducirlos y administrarlos en las aplicaciones digitales. Siendo necesaria la constitución de una nueva metodología que no solo ordene sino que también corrija las carencias de los ficheros digitales. En consecuencia, por medio de un caso real, el archivo familiar Kati, se plantean dos procedimientos, la categorización y el etiquetado semántico, enfocados a resolver algunas de las dificultades que se generan tras la digitalización y que facilitan la preservación y divulgación de los archivos familiares en entornos digitales.

Palabras Clave: Archivo familiar Kati; Categorización digital; Etiquetado semántico.

\begin{abstract}
The recent trend that is increasing the visibility and preservation of family archive is producing a new challenge for archivists. Because as well as they ensure the management and physical conservation of this type of archives they have to introduce and manage them in digital apps. It is for these reasons that it is absolutely necessary the set up of a new methodology that not only arranges the digital archives but also corrects their deficiencies. Consequently, through a real case, the Kati family archive, two procedures are proposed, precisely the categorization and semantic tagging. Which there are focused on solving some of the difficulties that are generated after digitalization and facilitate the preservation and dissemination of the files in digital environments.
\end{abstract}

Keywords: Kati family archive; Digital categorization; Semantic tagging. 


\section{Introducción}

A causa del mayor interés y estudios realizados en torno a los archivos familiares, principalmente desde la última década del siglo $\mathrm{XX}$, actualmente se está dando una tendencia que está impulsando la preservación de los fondos documentales reunidos por familias, que no tienen que ser obligatoriamente de origen nobiliario. Este factor está generando la formación de un patrimonio documental bastante rico que está facilitando no solo el estudio de los acontecimientos más conocidos, con los archivos nobiliarios, sino que también los ocurridos en lugares concretos que hasta ahora han pasado desapercibidos.

Esta situación está produciendo un nuevo desafío para los archiveros ya que además de procurar la organización, clasificación y conservación física de esta tipología de archivos, tienen que introducirlos a los repositorios digitales por medio de la digitalización. Siendo necesaria la constitución de una nueva metodología que no solo ordene sino que también corrija las carencias de los ficheros digitales, entre otras, la pérdida de relaciones y vínculos que poseen los documentos en soportes tradicionales.

En consecuencia, durante los siguientes apartados a través de un caso real, en concreto el archivo familiar Kati, se proponen dos técnicas enfocadas a facilitar la preservación y divulgación de los archivos familiares en entornos digitales. En particular, la categorización por medio del cuadro de clasificación y la identificación y vinculación a través del etiquetado semántico.

\section{El archivo familiar Kati o Fondo Kati}

Un ejemplo de archivo familiar es el patrimonio documental formado desde principios del siglo XVI por los descendientes de Ali b Ziyad al-Quti y su hijo Mahmud Kati. Este patrimonio familiar se denomina archivo familiar Kati o Fondo Kati porque tal y como se ha indicado lo crearon los miembros del clan Kati, principalmente en Tombuctú (Mali), a partir de los manuscritos que generaban y también con los que compraban o conseguían. Si bien, antes de que Ali se estableciera en Tombuctú a finales del siglo XV, la familia Kati vivió en los reinos de la Península Ibérica donde empezó a reunir la documentación que relataba su historia, labores y los acontecimientos vividos.

Desde un punto de vista europeísta, la importancia de este archivo y el principal motivo del interés para su preservación radican en su contenido tan singular y en su valor para reconstruir la historia de la cultura andalusí y judaica durante la Edad Media en la Península Ibérica. No obstante, también se considera una rica fuente de información sobre la historia del África Subsahariana, en concreto del Imperio Songhay. En definitiva el Fondo Kati no solo es el legado histórico de una familia sino que también es aconsejable considerarlo como bien de interés nacional e internacional por ser una de las pocas fuentes directas que trata sobre los asuntos indicados.

A consecuencia de los sucesos ocurridos durante los pasados siglos, en particular en el siglo XIX y principios del XX, todo el patrimonio reunido por los Kati se dispersó entre los miembros de la familia, cada cual guardándolo en lugares secretos que habitualmente eran sitios donde no estaba garantizada su preservación, agravando de esta manera sus problemas de conservación (Diadié Haidara y Pimentel, 2017). Hasta que Ismäel Diadié Haidara, actual responsable del Fondo, decidió continuar con la misión comenzada por su padre, fundamentada en la recuperación del patrimonio familiar, para poder darlo a conocer al mundo académico y conseguir ayudas para mejorar su situación y garantizar su preservación. Estas ayudas, y también colaboraciones, se han sucedido de dos formas diferentes. Por un lado, aquellas que 
fomentan la conservación del Fondo en su ubicación original, es decir en Tombuctú. Cabe subrayar la subvención valorada en 120.000 dada por el Junta de Andalucía en 2002 para la construcción en Tombuctú de un edificio que albergara la documentación de la familia (BOJA 125, 2002). Por el contrario, las que con acuerdos o tratados de colaboración mueven de Tombuctú el patrimonio familiar con fines específicos. Por ejemplo, al Instituto Andaluz del Patrimonio Histórico, en Sevilla, para la restauración de cinco manuscritos andalusíes, o asimismo, a la ciudad de Cádiz para su conservación temporal, exposición y estudio (La Fundación Fondo Kati tendrá sede en la provincia de Cádiz antes de que termine el año 2019, 2018).

Resumidamente y dejando a un lado los aspectos más físicos, en la actualidad el archivo familiar Kati es un archivo histórico que consta de aproximadamente 12.000 documentos. Están escritos principalmente por autores de origen árabe y en árabe aunque también se identifican autores y lenguas no arábigas, como el romance castellano. Asimismo, a pesar de que la documentación no solo procede de la familia Kati, ya que como es habitual en esta clase de archivos los Kati obtuvieron los patrimonios documentales de otros linajes o familias, se perciben tipologías documentales similares, por ejemplo: títulos de propiedad, actas de matrimoniales y de pleitos, correspondencia personal y comercial, etc. En concreto, estas semejanzas en la tipología documental facilitan los procesos que en el próximo apartado se describen.

Pese a la labor realizada por Ismäel Diadié, la preservación del patrimonio de los Kati sigue estando en peligro debido principalmente a dos motivos. Por un lado, las amenazas externas intentan localizar el Fondo Kati bien para destruirlo o bien para robarlo y venderlo en el mercado negro. Estas situaciones han generado la detención de las ayudas recibidas para afianzar el Fondo en Tombuctú y la vuelta al anonimato. Por otro lado, si continúan los problemas ocasionados por el depósito de la documentación en espacios inapropiados se puede llegar a producir la pérdida parcial o completa de la información que contienen.

Reflexionando sobre la acción más eficaz y legalmente admisible para mejorar la continuidad del patrimonio documental Kati, resulta que la opción más clara es su digitalización y posterior preservación digital. Puesto que además de conseguir una copia digital del fondo se mejoraría el estado físico de los documentos y se conocería la extensión y el valor exacto del Fondo, gracias a los procedimientos que se llevarían a cabo previos a la digitalización. No obstante, esta opción tiene sus problemas o limitaciones, como el lugar donde realizar la captura digital o las autorizaciones para su gestión digital, que se tienen que solucionar antes de poder efectuarlo.

\section{Técnicas para categorizar y vincular los manuscritos digitales.}

Entre los diversos procedimientos a realizar durante la digitalización y posterior administración digital de las copias digitales, cabría subrayar el diseño del cuadro de clasificación, junto con la ordenación de la documentación según este esquema, y el etiquetado semántico. Debido a su importancia en el proceso para la recuperación de las relaciones y vínculos que posee la documentación original, los cuales se pierden en la captura digital.

\subsection{La categorización del fondo.}

En primer lugar, el cuadro de clasificación es la herramienta por la cual se basa la organización del fondo documental. Se suele optar entre dos tipologías, o bien la funcional basada en la finalidad u objetivos con los que se generaron los expedientes, o 
bien por materias fundamentado en la tipología documental o en la temática que posee la documentación (Mastropierro, 2006).

En concreto, para el archivo familiar Kati se decide emplear un cuadro de clasificación por materias asentado en las tipologías documentales que se distinguen en el fondo, creando tantas secciones como productores se identifican. Es decir, por cada productor se utiliza las mismas unidades documentales diseñadas en el cuadro de clasificación. Un ejemplo de cuadro de clasificación válido para el Fondo Kati, siempre y cuando se realicen algunas modificaciones, especialmente en aspectos culturales y religiosos, es el cuadro propuesto por Borja Aguinagalde (Aguinagalde, 1992):

Tabla 1: Cuadro de clasificación por materias

\begin{tabular}{|c|c|}
\hline Sección & Serie \\
\hline Genealogía-Heráldica & $\begin{array}{l}\text { 1.1. Certificación de Escudos de Armerías } \\
\text { 1.2. Certificación de nobleza, genealogía y armas } \\
\text { 1.3. Probanza de nobleza } \\
\text { 1.4. Cuadros genealógicos } \\
\text { 1.5. Obras genealógicas, manuscritos o impresas } \\
\text { 1.6. Noticias o dibujos sobre armerías }\end{array}$ \\
\hline Pleitos & $\begin{array}{ll}2.1 . & \text { Autos originales } \\
2.2 . & \text { Real Carta Ejecutoria } \\
\text { 2.3. } & \text { Memoriales ajustados } \\
2.4 . & \text { Informaciones de testigos } \\
2.5 . & \text { Informes jurídicos y memoriales de abogados }\end{array}$ \\
\hline Transmisión de bienes & $\begin{array}{l}\text { 3.1. } \text { Contrato matrimonial } \\
\text { 3.2. Dotes matrimoniales y religiosas } \\
\text { 3.3. Testamento } \\
\text { 3.4. Codicilo } \\
\text { 3.5. Fundación de Mayorazgo } \\
\text { 3.6. Donaciones } \\
\text { 3.7. Cesiones } \\
\text { 3.8. Inventario de bienes } \\
\text { 3.9. Partición de bienes } \\
\text { 3.10. Tutela o curaduría } \\
\text { 3.11. Renuncias } \\
\text { 3.12. Poderes } \\
\text { 3.13. Carta de pago } \\
\text { 3.14. Mejora de tercio y quinto }\end{array}$ \\
\hline Administración de patrimonio & $\begin{array}{ll}\text { 4.1. } & \text { Almoneda } \\
\text { 4.2. } & \text { Apenamiento } \\
\text { 4.3. } & \text { Arrendamiento } \\
\text { 4.4. } & \text { Carta de pago } \\
\text { 4.5. } & \text { Compra } \\
\text { 4.6. } & \text { Contrato } \\
\text { 4.7. } & \text { Correspondencia } \\
\text { 4.8. } & \text { Cuentas } \\
\text { 4.9. } & \text { Hipoteca } \\
\text { 4.10. } & \text { Imposición de censo } \\
\text { 4.11. } & \text { Juro } \\
\text { 4.12. } & \text { Libramiento }\end{array}$ \\
\hline
\end{tabular}




\begin{tabular}{|l|l|}
\hline & 4.13. Libros de administración \\
& 4.14. Obligación \\
& 4.15. Permuta \\
& 4.16. Planos \\
& 4.17. Poderes \\
& 4.18. Redención de censo \\
& 4.19. Recibo \\
& 4.20. Traspaso \\
& 4.21. Venta \\
\hline Actividad pública & \\
\hline Correspondencia personal & \\
\hline Honores y privilegios & 7.1. Mercedes diversas \\
& 7.2. Cartas de sucesión o confirmación \\
& 7.3. Nombramiento para cargo público \\
\hline Relación con la Iglesia & 8.1. Certificación de Partida sacramental \\
& 8.2. Documentos de Patronato \\
& 8.3. Fundación de capellanía u Obra Pía \\
& 8.4. Reparto de dotaciones de Obras Pías \\
\hline Varios & \multicolumn{2}{|}{} \\
\hline
\end{tabular}

Además de organizar, a través del cuadro de clasificación se categorizan todos los documentos que forman el Fondo Kati siendo posible agruparlos en las mismas unidades documentales, en otras palabras secciones y series. Es decir, gracias al emparejamiento de documentos con similares características, en este caso basado en la tipología documental y en un segundo nivel en la temática, se consigue agrupar en un único nivel toda la documentación que comparte la misma tipología documental. Facilitando de esta manera su recuperación y relación con el resto de los expedientes de la unidad. Puesto que se agiliza su localización al poder ser buscado a través de la clase documental y mediante el lenguaje que se crea a partir del cuadro de clasificación. A modo de ejemplo, cualquier documento que trate sobre cesión de bienes entre familiares o personas ajenas a la familia se estructura en torno a la sección de transmisión de bienes, separándose según su tipología en las diferentes series como las formadas por los testamentos, contratos matrimoniales o la división de bienes. Esta última clase agrupa tanto notas, cuentas y acuerdos.

\subsection{La etiquetación semántica.}

Por otro lado, a diferencia del etiquetado identificativo, es decir las signaturas que otorgan valores únicos e irrepetibles, el etiquetado semántico facilita las relaciones entre ficheros por medio de palabras claves compartidas. Asimismo, aumenta el valor del patrimonio al simplificar la recuperación y visualización de los documentos que lo forman. Este etiquetado se genera a través de la creación de una estructura digital compuesta por nodos generales (término genérico) y específicos (término preferido), relacionados entre ellos. Estos nodos están formados por palabras claves que definen la descripción correspondiente a una propiedad identificada del fondo (Marzal GarcíaQuismondo, 2016). Estas etiquetas son más eficaces si se originan desde un vocabulario específico que esté fundamentado en un lenguaje especializado con las formalidades y fortalezas que le aporta la estructura de un lenguaje documental tan coherente como un tesauro. 
En el caso que nos concierne, los nodos o términos se crean a partir de la terminología utilizada en el diseño del cuadro de clasificación del Fondo Kati, si bien con el fin de completarlos se añaden descriptores correspondientes a otras cualidades de los documentos, tal y como se observa en la siguiente tabla:

Tabla 2: Ejemplo de descriptores al estilo de un tesauro

\begin{tabular}{|l|l|l|l|l|}
\hline $\begin{array}{l}\text { T. } \\
\text { Especifico }\end{array}$ & $\begin{array}{l}\text { T. } \\
\text { Genérico }\end{array}$ & $\begin{array}{l}\text { T. } \\
\text { Asociados }\end{array}$ & Grupo & Descripción \\
\hline Codicilo & Testamento & $\begin{array}{l}\text { Hijuela } \\
\text { Poderes } \\
\text { Herencia }\end{array}$ & $\begin{array}{l}\text { Transmisión de } \\
\text { bienes }\end{array}$ & $\begin{array}{l}\text { Última voluntad que no contiene } \\
\text { la institución del heredero y que } \\
\text { puede otorgarse en ausencia de } \\
\text { testamento o como complemento } \\
\text { de él (RAE). }\end{array}$ \\
\hline Hijuela & $\begin{array}{l}\text { División de } \\
\text { bienes }\end{array}$ & $\begin{array}{l}\text { Codicilo } \\
\text { Poderes } \\
\text { Herencia }\end{array}$ & $\begin{array}{l}\text { Transmisión de } \\
\text { bienes }\end{array}$ & $\begin{array}{l}\text { Documento donde se resenan los } \\
\text { bienes que tocan en una partición } \\
\text { a cada uno de los partícipes en el } \\
\text { caudal que dejó un difunto } \\
\text { (RAE). }\end{array}$ \\
\hline
\end{tabular}

A modo de aclaración, los dos términos, codicilo e hijuela, pertenecen a los grupos formados con los términos vinculados con las locuciones testamento y división de bienes pertenecientes al nodo de trasmisión de bienes. Y a pesar de que no coincidan en el término genérico comparten locuciones relativas ya que tanto codicilo e hijuela como poder y herencia están asociadas con la tipología documental de herencias y sucesiones.

En definitiva, al emplear las etiquetas semánticas además de proporcionar al Fondo Kati de las ventajas propias que genera el tesauro y de recuperar las carecían causadas por la digitalización, se proporciona una relación más segura entre los documentos que forman las unidades documentales y facilita también su vinculación con aquellos expedientes que aunque no se clasifican en la misma unidad comparten propiedades. Del mismo modo, las etiquetas agilizan la localización y recuperación de los expedientes ya que los sistemas de administración digital y los buscadores se basan o permiten la búsqueda mediante descriptores.

\section{Conclusiones}

Tal y como se indica, el procedimiento más eficaz y menos dañino para la preservación de los archivos, no solo los familiares, es la digitalización y su posterior gestión mediante aplicaciones tecnológicas. No obstante, para evitar cometer daños tanto en la documentación original como en las copias digitales es necesario, por un lado, adoptar ciertas pautas y técnicas basadas en la metodología archivista pero ajustadas a las características del archivo, y por otro lado, respetar las necesidades de cada procedimiento y la legislación. Con especial relevancia en el método por el cual la documentación se deposita en la institución que va a llevar a cabo la digitalización, sobre todo con los archivos familiares que poseen su origen en el extranjero, como es el caso del Fondo Kati.

Entre todos los procesos a realizar durante la digitalización se han destacado y explicado la categorización a través del cuadro de clasificación y el etiquetado semántico porque gracias a la aplicación y buen uso de ambas herramientas es posible paliar la mayoría de los inconvenientes o riesgos que se producen en la digitalización de cualquier archivo familiar. Si bien, ambos procedimientos se deben empezar a realizar 
antes de proceder con la digitalización ya que el diseño tanto del cuadro de clasificación como de los nodos requieren del conocimiento completo del alcance del fondo.

\section{Bibliografía}

Aguinagalde Olaizola, F. B. (1992). Los Archivos de familia definición, estructura, organización lección de ingreso en la R.S.B.A.P. Nuevos extractos de la R.S.B.A.P., 5, 9-35.

Diadié Haidara, I.; Pimentel, M. (2017). Diario de un Bibliotecario en Tombuctú. Córdoba: Almunzara.

La Fundación Fondo Kati tendrá sede en la provincia de Cádiz antes de que termine el año 2019 (7 de agosto de 2018). Europa Press. Recuperado de https://www.europapress.es/andalucia/cadiz-00351/noticia-fundacion-fondokati-tendra-sede-provincia-cadiz-antes-termine-ano-2019-20180807143952.html (Consultado el 16-05-2019).

Marzal García-Quismondo, M. A. (2016). Tesauros, vocabularios y listas de control terminológico. Fuentes para la construcción de tesauros culturales. En El lenguaje sobre el patrimonio. Estándares documentales para la descripción y gestión de colecciones (pp. 93-104). Ministerio de la Educación, Cultura y Deporte.

Mastropierro, M.C. (2006). Archivos privados: análisis y gestión. Buenos Aires: Alfagrama.

Real Academia de la Lengua. (2018). Diccionario de la lengua española. Recuperado de http://dle.rae.es/index.html (Consultado el 31-12-2018).

Resolución de 4 de octubre de 2002, de la Secretaría General Técnica, por la que se hace pública la concesión de la subvención de carácter excepcional que se cita. Boletín Oficial de la Junta de Andalucía. Sevilla, 26 de octubre 2002, núm. 125, pp. 20.796. 